\title{
Wound Image Analysis of Sickle Cell Anemia
}

\author{
Dr. Hariharan S. \\ Professor \\ Department of Electrical Engineering \\ College of Engineering Trivandrum, Kerala, India \\ Aruna N.S. \\ Department of Electrical Engineering \\ College of Engineering Trivandrum, Kerala, India
}

\begin{abstract}
Wounds are common in the case of accidents or diseases such as diabetes, sickle cell anemia etc. Physicians involved in the treatment of such patients are always eager to see whether the wounds are healing as fast as possible. Computerized image analysis techniques can help such medical practitioners by clearly showing the pictures of wound before and after treatment or at a particular interval of time to make them aware of their treatment results or confidence in the treatment with mathematical support.
\end{abstract}

Keywords - leg ulcer, sickle cell anemia, template matching, wound area measurement.

\section{INTRODUCTION}

Wound image analysis is important in sickle cell anemia. The manifestations of this disease are diverse. Among them leg ulceration is common and can be disabling. Sickle cell anemia is first detected in the year 1910. Even the first patient reported above had chromic leg ulceration [1]. Leg ulcers can be classified as acute or chronic according to their duration. An acute ulcer usually heals in less than a month. In chronic ulcers takes duration of six months or more for healing the wound. Leg ulcers prevention is also very important in the case of Sickle cell disease (SCD) patients. Studies have shown that zinc deficiency is common in individuals with sickle cell disease. This mineral is found to play an important role in immune function and wound healing. Some studies showed that administration of zinc sulphate resulted in more rapid healing of leg ulcers [2]. Medical professionals have conducted serious and series of studies in the field of wound image analysis. As a result many encouraging results are found [3 to 6]. Engineering scientists and biomedical engineers have also contributed significantly in the field of wound image analysis [7 to 13]. There are several approaches for the characterization and recognition of these images. They found that grey level image analysis alone will not be sufficient for the analysis of leg ulcers. Different parts of image have different colors and hence by identifying colors, it is possible to classify different types of tissues. This will help the physicians for identifying the status of wound healing.

Measurement of wound area is found to be an excellent method for studying the progress of wound healing. The latest development in the field of wound image analysis is the automatic measurement of wounds. The advantages of automatic wound measuring are reducing workloads, save money and give an objective assessment of wound healing. The primary objectives of automatic measuring system are the tissue classifications and have been reported in [8to 13]. Researchers started working in this direction as early as in the year $2000[14,15,16]$. Reliability studies on wound surface area measurement have been performed by C.Majeske [14]. A comparative study of three clinically useful methods for wound area measurement have been performed by A.C.Thomas and A.B.Wysocki[16]. Sonja and Niall developed ruler based method, transparency tracking, photographic method and digital video methods [17]. They have also identified that research is required to develop effective methods which enhance wound healing, reduce associated pain and improve the quality of life of patients. [18] Another approach is to study the tissue characteristics, temperature and smell [19]. Some other studies concentrate on the visual characteristics of the internal tissues of the ulcer.

One of the important contributions in the field of ulcer measurement is by using active contour model by T.D.Jones and Peter Plassmann. Various aspects of wound measurement have been studied by Plassmannn [20]. Measurement of physical dimensions of wound has been performed by [21, 22, 23, 24]. Deformable contours have been used for modeling and extraction by Lai and Chin [24]. Xu and Prince [25] used snakes, shapes and gradient vector flow for wound area measurement. Comparison of different imaging techniques have been presented by Nila B. and Nagdev [26]. Enhanced assessment of wound healing process by accurate multi view tissue classification was developed by Hazen and Yves [27]. 


\section{MATERIALS AND METHODS}

Wound image is segmented using a modified template matching technique. This is followed by a measurement of wound area. Convex hull method implemented in Matlab is used for finding the area and perimeter of the wound.

\section{Template matching}

Template matching is one of the most important and classical technique in digital image processing used for item detection and pattern matching. In this method a comparison is made with the template image and reference image to find a similarity matrix. Template is widely used in biomedical engineering for the processing of images of internal organs. These are various methods in template matching. These include (a) Sum of absolute difference, (b) Sum of squared difference, (c) Normalized cross correlation (NCC), (d) Maximum absolute difference etc. In this work this work correlation is used to determine the existence of a shape in an image. Classical correlation takes in to account the mean of the template and image area under the template as well as the spread of values in both template and image area. If the overall light intensity across the image is constant, we can use convolution instead of correlation. Correlation can be converted in to convolution as shown below.

If $N \times M$ image is indicated by $I(X, Y)$ and $n \times m$ template is addressed by $\mathrm{t}(\mathrm{i}, \mathrm{j})$

$$
\begin{aligned}
\operatorname{corr}(X, Y) & =\sum_{i=0}^{n-1} \sum_{j=0}^{m-1}[t(i, j)-I(X+i, Y+j)]^{2} \\
& =\sum_{i=0}^{n-1} \sum_{j=0}^{m-1}\left[t(i, j)^{2}-2 t(i, j) I(X+i, Y+j)+I(X+i, Y+j)\right]^{2} \\
& =\sum_{i=0}^{n-1} \sum_{j=0}^{m-1} t(i, j)^{2}-2 \sum_{i=0}^{n-1} \sum_{j=0}^{m-1} t(i, j) I(X+i, Y+j)+\sum_{i=0}^{n-1} \sum_{j=0}^{m-1} I(X+i, Y+j)^{2}
\end{aligned}
$$

The first term of equation (3) is constant across the image, So can be ignored. The last term is constant only if average higher from image is constant across the image. The middle term indicates t convoluted with $i$.

\section{Wound area measurement}

a. Area of the object: This is the sum of partial areas $A_{c 1}$ and $A_{c 2}$

$$
\begin{aligned}
& A_{\mathrm{c} 1}=\int \mathrm{g}\left(\mathrm{Y}_{2}\right) \mathrm{d} \mathrm{Y}_{2} \mid \mathrm{Y}_{2}>0 \\
& \text { and } \\
& \mathrm{A}_{\mathrm{c} 2}=\int \mathrm{g}\left(\mathrm{Y}_{2}\right) \mathrm{d} \mathrm{Y}_{2} \mid \mathrm{Y}_{2}<0 \\
& \text { Area }=\mathrm{A}_{\mathrm{c} 1}+\mathrm{A}_{\mathrm{c} 2}
\end{aligned}
$$

b. Perimeter of the object: Perimeter of the object is given by

$$
\text { Perimeter }=\int \mathrm{dY}_{2}
$$

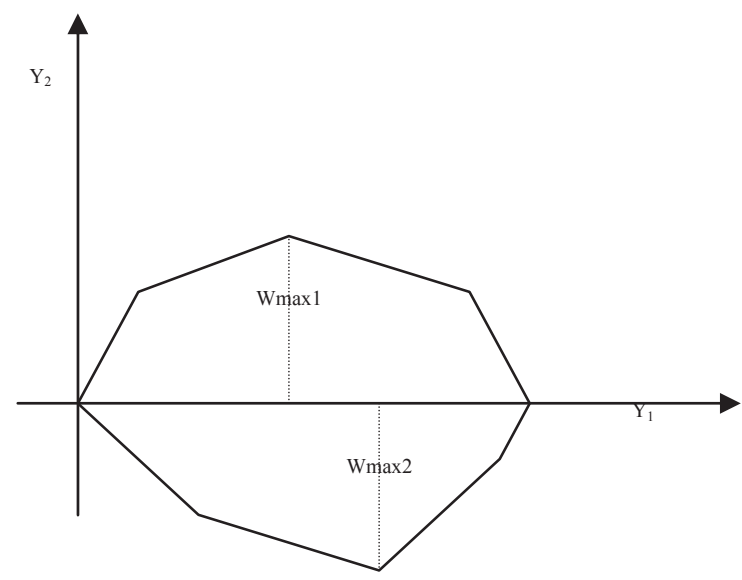


Fig 1. Plot of Convex Hull measurement of area and perimeter

The wound area is first computed using convex hull method from the wound image. After each week the wound area is again computed using the same method. This is continued until the wound gets cured. If there is a reduction in area then we can realize that that the wound is healing. If the wound area is same or more, then we can infer that the wound did not heal properly. If the wound area is becoming large, then wound is not healing and is going for complication. In order to find wound area we adopt convex hull technique implemented in the software Matlab-2014a. From this we will be able to find the area of wound and perimeter directly.

\section{RESULTS AND DISCUSSION}

Sickle cell anemia is a heritable blood related disorder which is caused by lack of red blood cells (RBC) in the blood smear. In this disease RBC shape is changed to half-moon shape which blocks the flow of blood in small blood vessels in the body. This will cause obstruction of blood flow which in turn causes ulcers in the lower limb below the knee. The treatment of these wounds by the leg ulcers is difficult to manage and time consuming. Hence frequent care is required for these patients. The physicians are also anxious to see whether the wound is healing or not.

In this work we first segment the SCD affected wound image using digital image processing technique. Analysis of the region of the interest (ROI analysis process) is essential and required for the detailed study of wound healing. For the purpose of segmentation we use a modified form of template matching technique. Image segmentation subdivides an image in to its constituent parts so that one can clearly see the various types of tissues in the wound image. Image segmentation is a high level computer vision technique, commonly employed for the image process community and separates the wound area clearly. This is followed by the measurement of wound area. Now the wound area is computed using convex hull method implemented in Matlab R2014a.

Fig 2,3,4,5 and 6 are wound images of sickle cell anemia patients. They are affected in the lower limb and developed as leg ulcer. The treatment of the leg ulcer is extremely difficult and takes long time for curing. Hence they need frequent care and continuous medical attention or hospitalization. Template matching technique are applied on these images and the corresponding output image is obtained are shown in fig 2(c), 3(c), 4(c), 5(c) and 6(c) respectively. From these images, region of interest is selected and convex hull method is applied in the wound image for finding the wound area and perimeter. These two processes are very simple and also they are very much suitable for implementing in the clinical environment.

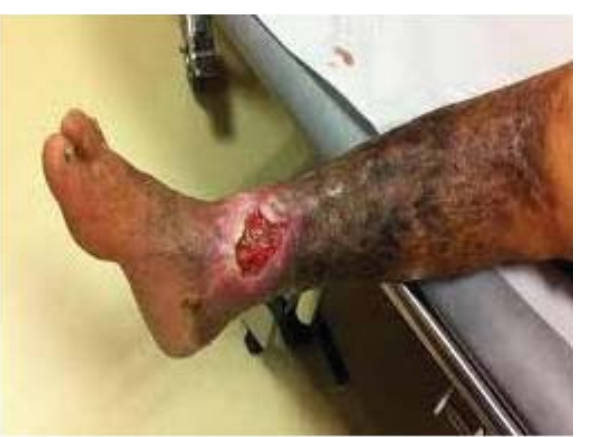

(a)

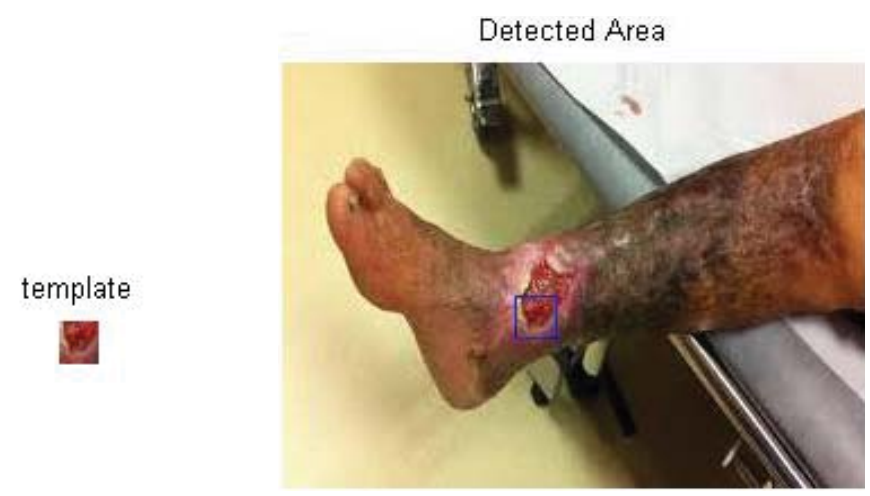

(b)

(c)

Fig 2. (a) Original image (b) template selected (c) selected template detected area in original image 


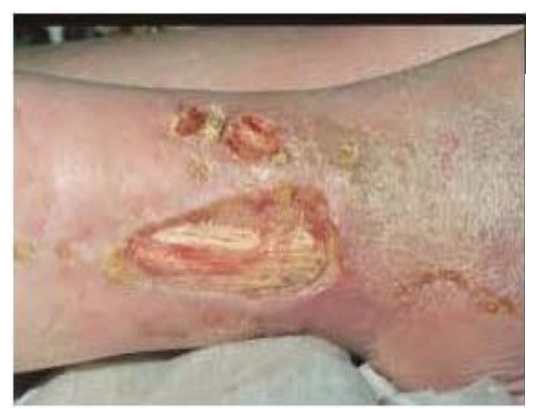

(a)

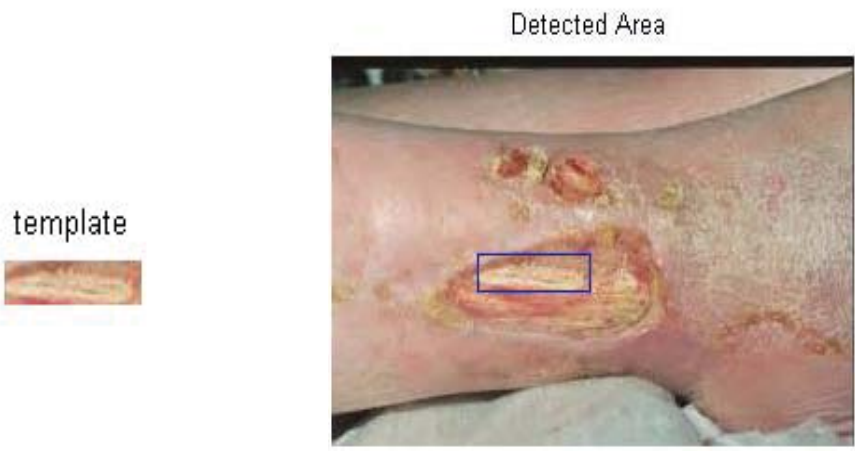

(b)

(c)

Fig 3.(a) Original image (b) template selected (c) selected template detected area in original image

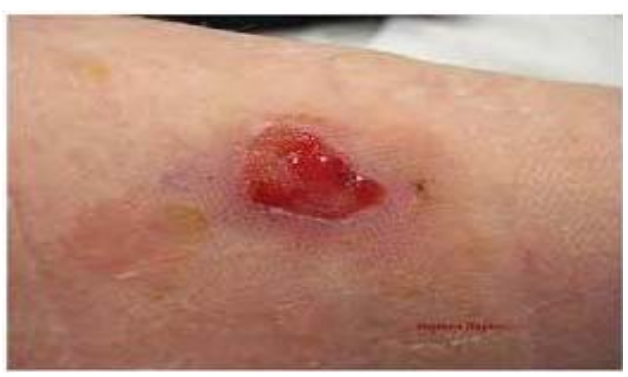

(a)

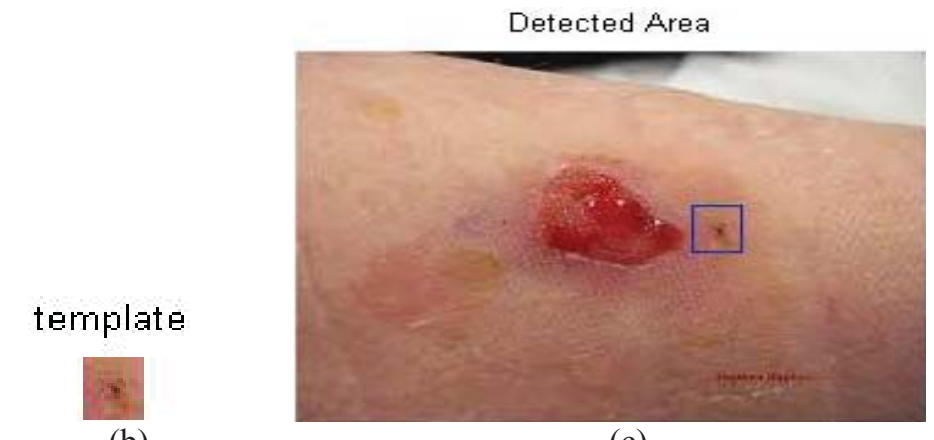

(c)

(b)

Fig 4. (a) Original image (b) template selected (c) selected template detected area in original image

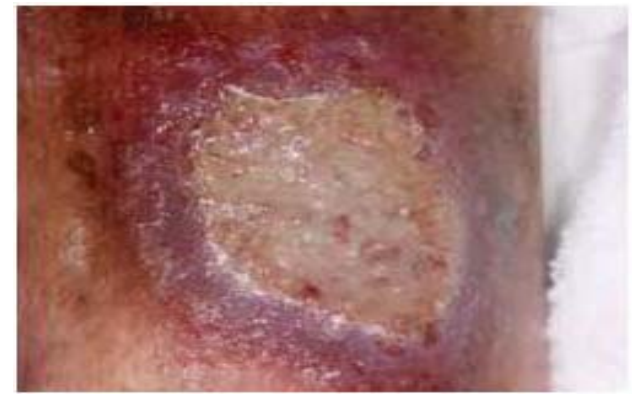

(a)
Detected Area

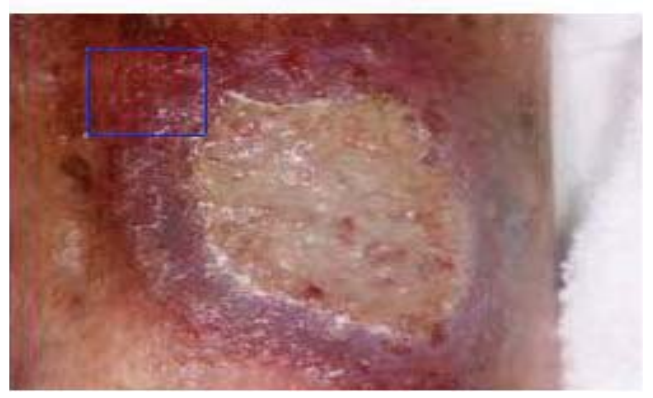

(c)

Fig 5. (a) Original image (b) template selected (c) selected template detected area in original image 


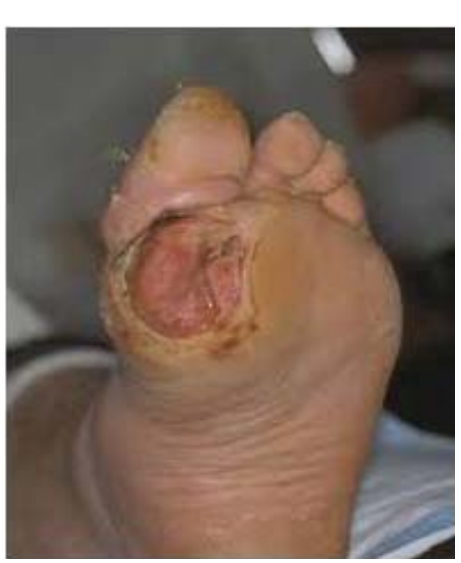

(a)

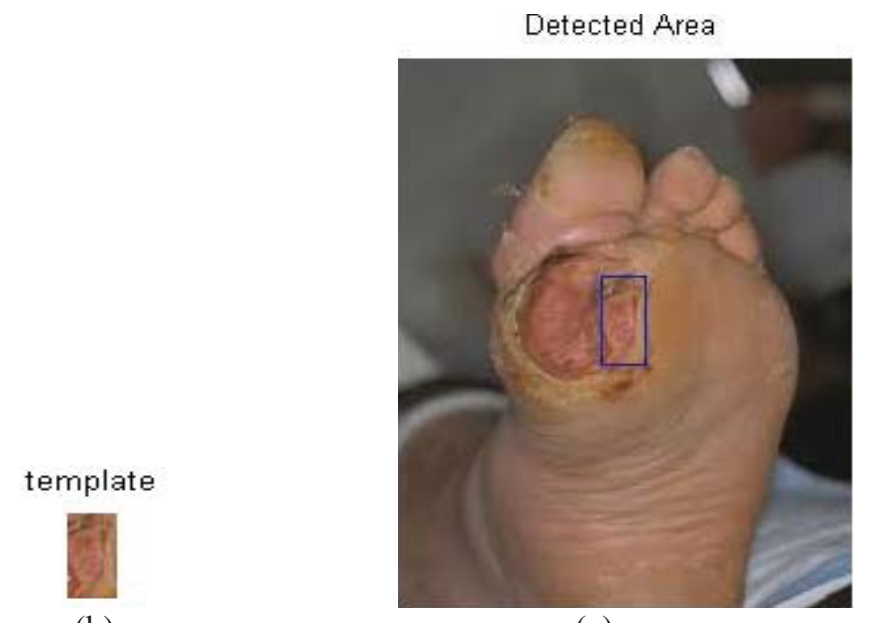

(b) (c)

Fig 6. (a) Original image (b) template selected (c) selected template detected area in original image

\section{EXPERIMENTAL RESULTS}

Measurement of wound of five leg ulcer patients on adjacent weeks is shown in table 1. It points out the healing of wound on each adjacent week by taking medicines. The area and perimeter of the wounds are measured for each week to conclude whether the wound is healing or not. Area and perimeter of wound of each patient is measured and graphs are plotted against week of a month to compare how fast the healing is taking place. Fig 7 is the plot of area against time (in weeks) and fig 8 is the plot of perimeter against time (in weeks). These plots help the physicians to understand the condition of the wound. A decrease in wound area and perimeter shows the wound is healing otherwise, it is not healing. If the wound is not healing, then the physicians have to go for more medical care for the patient.

Table 1Measurement of wound area and perimeter

\begin{tabular}{|c|c|c|c|c|c|c|c|c|c|c|}
\hline \multirow{2}{*}{$\begin{array}{c}\text { Sl. } \\
\text { no }\end{array}$} & \multirow{2}{*}{$\begin{array}{c}\text { Patie- } \\
\text { nt no. }\end{array}$} & $\begin{array}{c}\text { Age \& } \\
\text { gender }\end{array}$ & \multicolumn{2}{|c|}{ Week 1 } & \multicolumn{2}{|c|}{ Week 2 } & \multicolumn{2}{|c|}{ Week 3 } & \multicolumn{2}{|c|}{ Week 4 } \\
$\left(\mathrm{mm}^{2}\right)$ & $\begin{array}{c}\text { Perimeter } \\
(\mathrm{mm})\end{array}$ & $\begin{array}{c}\text { Area } \\
\left(\mathrm{mm}^{2}\right)\end{array}$ & $\begin{array}{c}\text { Perimeter } \\
(\mathrm{mm})\end{array}$ & $\begin{array}{c}\text { Area } \\
\left(\mathrm{mm}^{2}\right)\end{array}$ & $\begin{array}{c}\text { Perimeter } \\
(\mathrm{mm})\end{array}$ & $\begin{array}{c}\text { Area } \\
\left(\mathrm{mm}^{2}\right)\end{array}$ & $\begin{array}{c}\text { Perimeter } \\
(\mathrm{mm})\end{array}$ \\
\hline 1 & $\mathrm{P} 1$ & $\begin{array}{c}37 \\
\mathrm{~F}\end{array}$ & 112 & 0.68 & 88 & 0.5 & 76 & 0.38 & 52 & 0.22 \\
\hline 2 & $\mathrm{P} 2$ & $\begin{array}{c}21 \\
\mathrm{~F}\end{array}$ & 137 & 0.9 & 124 & 0.87 & 120 & 0.70 & 96 & 0.53 \\
\hline 3 & $\mathrm{P} 3$ & $\begin{array}{c}57 \\
\mathrm{M}\end{array}$ & 184 & 0.58 & 176 & 0.31 & 147 & 0.21 & 89 & 0.10 \\
\hline 4 & $\mathrm{P} 4$ & $\begin{array}{c}42 \\
\mathrm{~F}\end{array}$ & 150 & 0.87 & 120 & 0.76 & 87 & 0.62 & 62 & 0.42 \\
\hline 5 & $\mathrm{P} 5$ & $\begin{array}{c}62 \\
\mathrm{M}\end{array}$ & 186 & 0.69 & 172 & 0.51 & 169 & 0.49 & 57 & 0.33 \\
\hline
\end{tabular}




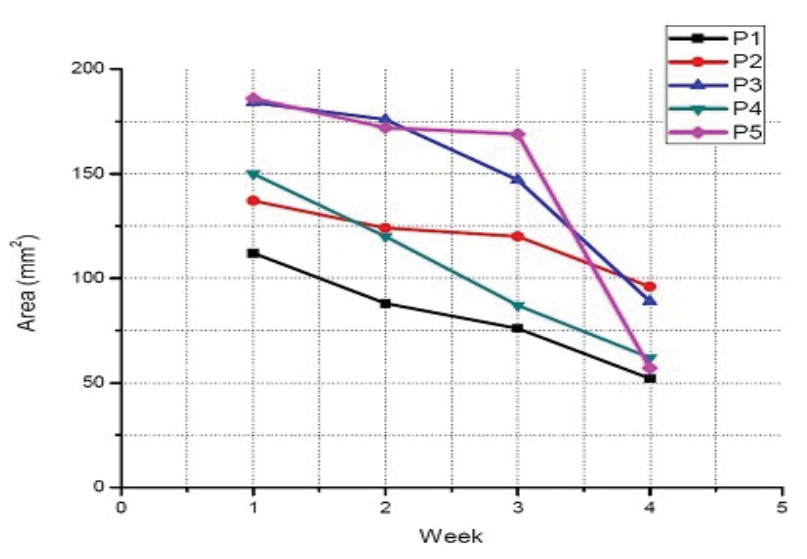

Fig 7 Plot of wound area measurent of the patients

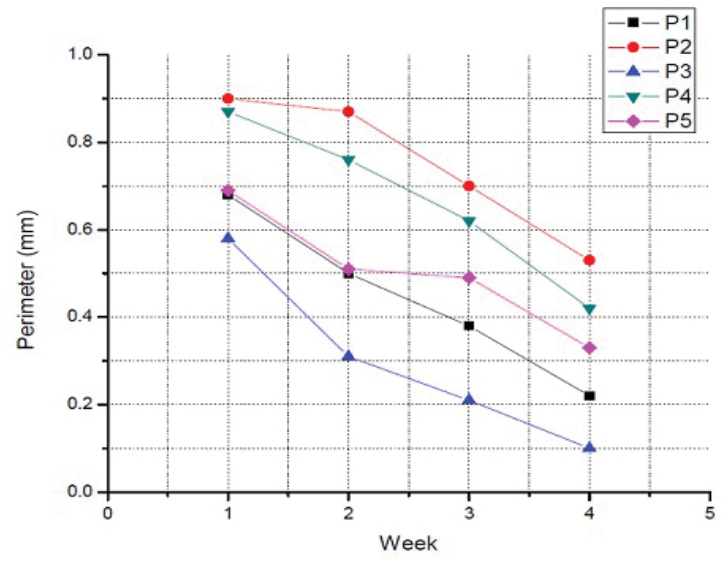

Fig 8. Plot of wound perimeter measurent of the patients

\section{CONCLUSION}

Wound healing is not a very simple mechanism. But it is a complex process, which involves a series of mechanisms taking place in the body. The patients and the physician involved in the treatment are very much interested and always anxious to see whether the wound is healed or not. In this paper a method is proposed for the analysis of wound images which segments the wound area with modified template matching. This is followed by the measurement operation using convex hull method. The original leg ulcer images of SCD affected patients with wound and their segmented version are shown in fig 2, 3, 4, 5 and 6 . These segmented images after applying modified template matching are shown in fig 2(c), 3(c), 4(c), 5(c) and 6(c) respectively. Wound area can be selected manually or automatically. Convex hull algorithm implemented in the MATLAB R2014a is applied on the above image and results are shown. The physician can see these images and at a particular interval of time again the process is repeated. The success in the treatment of the disease or progression of the disease can be quantitatively observed from the area calculated by the convex hull method.

\section{REFERENCES}

[1] Herrick JB "Peculiar elongated and sickle shaped red blood corpuscles in a case of severe anemia 1910", The Yale Journal of biology and medicine, 179-184, 2001.

[2] Serjeant G R, Galloway R E, Gueri MC, “Oral zinc sulphate in sickle -cell ulcer” lancet, :2:891-892, 1970.

[3] Sergeant G R., "Leg ulceration in sickle cell anemia” Archives of internal medicine. 133:690-694.[PubMed:4818436], 1974.

[4] Koshy M, Entsuah R, Koranda A, Kraus A P, Johnson R, Bellvue R, Flournoy - Gill Z,LevyP. "Leg ulcers in patients with sickle cell disease" Blood 74:1403 -1408.[PubMed:2475188]1989.

[5] Trent J T, Kirsner RS, "Leg ulcers in sickle cell disease" Advances in skin \&wound care, 17:410-416.[PubMed:15492676],2004

[6] Serjeant GR, Serjeant BE, Mohan JS, Clare A. "Leg ulceration in sickle cell disease:medieval medicine in a modern world" Hematology /oncology clinics of North America 19:943-956.viii-ix[ PubMed:16214654] , 2005.

[7] Aruna.N.S, Hariharan.S “Color Image Analysis of Leg Ulcer” IEEE International Conference on Knowledge Collaboration in Engineering, 2014.

[8] M Herbin, F.X. Bon, A. Venot, F. Jeanlouis, M.L. Dubertret, and D. Strauch, "Assessment of healing kinetics through true color image processing," IEEE Transactions on Medical Imaging, vol. 12, no. 1, pp. 39-43, 1993.

[9] J. Mekkes and W. Westerhof "Image processing in the study of wound healing," Clinics in Dermatology, vol. 13, no. 4, pp. 401-407, 1995.

[10] B. F. Jones and P. Plassmann, "An instrument to measure the dimensions of skin wounds," IEEE Trans. Biomed. Eng., vol. 42, pp. 464470, May 1995.

[11] W.P. Berriss, “Automatic quantitative analysis of healing skin wounds using colour digital image processing,” World wide wounds (online), 1997.

[12] W.P. Berriss, "Acquisition of skin wound images and measurement of wound healing rate and status using colour image processing," PhD thesis, the University of Reading, 2000.

[13] M. Herbin, A. Venot, J.Y. Devaux, and C. Piette, "Colour quantization through image processing in skin," IEEE Transactions on Medial Imaging, vol. 9, no. 3, pp. 262-269, 1990.

[14] C. Majeske,"Reliability of wound surface area measurements," Phys. Therapy, vol. 72, no. 2, pp. 138-141, 1992.

[15] P. Plassmann, "Measuring wounds," J. Wound Care, vol. 4, no. 6, pp. 269-272, 1995. 
[16] A. C. Thomas and A. B. Wysocki, "The healing wound: a comparison of three clinically useful methods of measurement," Decubitus, vol. 3, no. 1, pp. 18-25, 1990.

[17] Sonja A. weber, Niall Watermann, Jacques Jossinet, J.Anthony Byrne , JonquilleChantrey, ShabanaAlam, Karen So, Jim Bush, Sharon O'Kane, and Eric T.McAdams "Remote Wound Monitoring Of Chronic Ulcers"," IEEE Transactions on Information Technology In Biomedicine, vol.14,no.2,.pp 371-377march 2010

[18] A.A. Perez, A.Gonzaga,Alves J. M., "Monitoring the treatment of leg ulcers through computer vision algorithms applied in color images". International Conference on Quality Control by Artificial Vision, EESC - ESCOLA DE ENGENHARIA DE SAO CARLOS, vol.2, pp. $516-521,2001$.

[19] Lucas C. Pereyra, S'ilvio M. Pereira, Juliana P. Souza, Marco A. C. Frade, Rangaraj M. Rangayyan, Paulo M. Azevedo-Marques "Characterization and pattern recognition of color images of dermatological ulcers: a pilot study", Computer Science Journal of Moldova, vol.22, no.2(65), 2014.

[20] T. D. Jones and P. Plassmann, "An active contour model for measuring the area of leg ulcers," IEEE Trans. Medical Imaging, vol. 19, pp. 1202-1210, Dec. 2000.

[21] T. D. Jones, "Improving the precision of leg ulcer area measurement with active contour models," Ph.D. dissertation, University of Glamorgan, Glamorgan, U.K., 1999.

[22] M. Kass, A. P. Witkin, and D. Terzopoulos, "Snakes: Active contour models," in Proc. 1st Int. Conf. Computer Vision, pp. 259-268, 1987.

[23] J. I. Kundin, "A new way to size up wounds," Amer. J. Nursing, vol. 89, no. 2, pp. 206-207, 1989.

[24] Kok F. Lai and Roland T. Chin,"Deformable contours: Modeling and extraction,” IEEE Trans. Pattern Analysis and Machine Intelligence, vol. 17, pp. 1084-1090, Nov. 1995.

[25] C. Xu and J. L. Prince "Snakes, shapes, and gradient vector flow," IEEE Trans. Image Processing, vol. 7, pp. 359-369, Mar. 1998.

[26] Nila B. Mankar,U.T.Nagdeve, "Comparision of different imaging techniques used for chronic wounds", IJRET Volume: 02 Issue: 07 | Jul2013.

[27] Hazem Wannous, Yves Lucas "Enhanced assessment of the wound-healing process by accurate multi-view tissue classification” IEEE Tran. on medical imaging vol.30, No.2, February 2011. 